Revista Iberoamericana. Vol. LXVI, Núm. 193, Octubre-Diciembre 2000, 815-819

\title{
LA CUESTIÓN DEL GÉNERO: PROPUESTAS OLVIDADAS Y DESAFÍOS CRÍTICOS
}

\author{
POR \\ SylVIA Molloy \\ New York University
}

Al comienzo de los Viajes de Sarmiento hay una escena que siempre me ha intrigado. Sarmiento, se recordará, en 1845 emprende un viaje desde Chile, donde se ha exiliado, rumbo a Europa. Se trata de un viaje principalmente utilitario — el gobierno de Montt lo envía en misión oficial para estudiar métodos de educación europeos- pero este objetivo pasa rápidamente a segundo lugar. El viaje de Sarmiento es menos viaje de documentación que viaje ilustrado, de instrucción personal, viaje civilizador, semejante, en ese sentido, a la ejemplar Educación de Henry Adams de su vecino del norte: es un viaje en el que el educando americano se ilustra en Europa a la vez que, como representante de "estas tierras lejanas” (6), educa a Europa acerca de su región. Pero no es mi propósito aquí hablar del viaje (aunque, para usar un término sobre el cual volveré a menudo, me divertiría hacerlo) sino examinar, como he dicho, un episodio cerca del comienzo a partir del cual propondré algunas reflexiones.

El relato se inicia con un prólogo en el que Sarmiento, con alguna impaciencia, discute el género de su texto (entiendo aquí género literario), consciente de que el viaje escrito corre el riesgo de contaminarse de ficción "a punto de no saberse si lo que se lee es una novela caprichosa o un viaje real” (3). Digo con alguna impaciencia, ya que Sarmiento aquí (como en todo lo que escribe) reclama para su escritura una veracidad y una utilidad patrióticas (los términos apenas difieren) que mal acomoda el capricho, las “ficciones de la fantasía” (6) que exceden y acaso cuestionan esa escritura servicial pro patria: escribir es hacer nación, no divertirse. Y sin embargo es por una de esas diversiones — entiendo el término literalmente, como un desvío- que comienza su viaje.

En su primera carta de viaje narra Sarmiento cómo, poco después de zarpar de Valparaíso, un “porfiado viento” (11) saca a la Enriqueta de su curso llevándola al archipiélago de Juan Fernández donde queda, presa de una calma de cuatro días, bogando junto a una de las islas, Más-afuera. Los viajeros deciden acercarse en botes y pasar el día en tierra pero, calculando mal las distancias, llegan a la costa al crepúsculo. El paseo se torna aventura insólita, "suministrándonos sensaciones para las que no estábamos apercibidos" (11). Gritos humanos, acaso de “desertores de buques u otros individuos sospechosos” (12), revelan a los viajeros que no sólo perros o cerdos salvajes pueblan la isla. Cuatro náufragos norteamericanos reciben a los viajeros con gozo, pues hace más de dos años no hablan con nadie. Encantado con este encuentro que confirma, con creces, su lectura del Robinson 
Crusoe de Defoe, Sarmiento describe esta pequeña comunidad idílica con lujo de detalle. Participa en las actividades de “aquella pastoral” (14), narra comidas y varoniles cacerías compartidas, se confiesa chambón en comparación con los otros (él es hombre de letras, no de armas) y alaba la sabia productividad de esta minisociedad como contrapartida utópica de la desordenada sociedad argentina de la cual ha sido exiliado. Estos cuatro hombres, anota Sarmiento, “viven felices para su condición”(21). Pero inmediatamente añade un curioso comentario: "Para que aquella incompleta sociedad no desmintiese la fragilidad humana, estaba dividida entre sí por feudos domésticos, cuya causa no quisimos conocer, tal fue la pena que nos causó ver a estos infelices separados del resto de los hombres, habitando dos cabañas a seis pasos la una de la otra, iy sin embargo, malqueriéndose y enemistados! Está visto: la discordia es una condición de nuestra existencia, aunque no haya gobierno ni mujeres” (21, énfasis mío). Digo curioso comentario porque Sarmiento, normalmente tan locuaz, tan deseoso de conocer todas las causas, tan afecto a exigir explicaciones cuando no a inventarlas, en una palabra, tan preguntón, en este caso se abstiene de indagar, de interpretar, guarda silencio: “cuya causa no quisimos conocer”. Este llamativo silencio se corresponde notablemente con la locuacidad excesiva de uno de los habitantes de esta pequeña comunidad, locuacidad que visiblemente irrita a Sarmiento: “A propósito de preguntas, este Williams nos explotó a su salvo desde el momento de nuestro arribo hasta que nos despedimos. [...] Williams [...] se apoderó de nosotros y se lo habló todo, no diré ya con la locuacidad voluble de una mujer, lo que no es siempre bien dicho, pues hay algunas que saben callar, sino más bien con la petulancia de un peluquero francés que conoce el arte y lo practica en artiste” (22, énfasis mío). El episodio concluye con la partida de Sarmiento y los suyos. Sólo uno de los hombres, un joven de dieciocho años, solicita la extradición y opta por regresar con ellos; los otros tres, de nuevo sin que se sepa por qué — 0 acaso sin que se quiera saber por qué—, eligen quedarse.

Resumo este notable incidente. Hay cuatro hombres en la isla que viven en dos cabañas en una economía doméstica echada a perder por la discordia. La discordia, según Sarmiento, es cosa de gobiernos o de mujeres, pero aquí no hay gobierno y sobre todo no hay mujeres: hay hombres. La situación parece inspirarle a Sarmiento una única reacción posible: el no preguntar acerca de la causa de esa discordia, el no querer conocer. Pero uno de esos hombres es particularmente irritante porque no respeta el silencio, habla demasiado, como una mujer. O mejor (para no hablar mal de las mujeres, dice Sarmiento), como un peluquero francés “artístico". La línea entre el silencio (del observador) y la volubilidad (del observado) se ve cruzada, cuestionada, por algo: ese algo es, precisamente, lo que no se quiere conocer (conocer la causa de la discordia conlleva el riesgo de conocer la norma de concordia vigente) y ese algo se manifiesta, insistentemente, a través del género (aquí no literario sino sexual). Esa manifestación a través del género excede el binarismo -la discordia es de mujeres pero aquí no hay mujeres, Williams habla tanto que parece una mujer pero no es una mujer- para culminar en una representación caricatural: el peluquero francés afectado, cifra abyecta de lo otro, de un "afeminamiento" que tampoco se quiere conocer pero que se intuye suficientemente para ridiculizarlo.

¿Por qué me detengo tanto en este relato al punto que le he dedicado más de la mitad de una exposición que lleva por título "La cuestión del género”? Intento responder: porque me parece emblemático de un tipo de lectura en Hispanoamérica que consiste en "no querer 
conocer”, como Sarmiento, planteos de género, sobre todo cuando ilumina, es decir vuelve reconocibles, sexualidades que hacen entrar en crisis representaciones de género convencionales, cuestionando su binarismo utilitario; un tipo de lectura que perpetuamente desplaza el debate sobre el género y sobre la crisis de representación del género al más afuera de los proyectos de cultura nacional. Previsiblemente, en el caso de Sarmiento, después de este incidente de Juan Fernández, ${ }^{1}$ se vuelve a la vía recta del viaje latinoamericano a Europa. La noción de que el desvío queda fuera de la reflexión provechosa, en el más afuera de la nación, se confirma en el juicio de Antonino Aberastáin, corresponsal de Sarmiento. Aberastáin opina que “[la] carta de la Isla de Más-afuera no vale gran cosa” y aconseja a Sarmiento "que en adelante escriba sobre cosas útiles, prácticas, aplicables a la América" (98, énfasis mío).

Tradicionalmente el género como categoría de análisis no ha gozado de la atención ni del respeto de la crítica latinoamericana. Baste leer las opiniones, sintomáticamente burlonas, de un reputado crítico, publicadas no hace mucho en El País de Madrid y Excélsior de México, para darse cuenta de que la desconfianza y el desprestigio perduran aun en su forma más burda. ${ }^{2}$ El género, en América Latina, sigue viéndose como categoría crítica no del todo legítima, hasta abyecta, a menudo postergada cuando no subordinada a categorías consideradas más urgentes. Es cierto que desde hace años se viene corrigiendo esa desconfianza y esa desatención: la abundancia de trabajos sobre género en este mismo congreso atestiguan ese esfuerzo crítico, explorando propuestas olvidadas y deteniéndose en los bordes de los planteos de género, en esos puntos de crisis donde las disidencias sexuales cuestionan las propuestas hegemónicas. Pero no es menos cierto-y la composición mayormente unigénere de los debates de género en América Latina lo atestigua- que subsiste una enorme resistencia, impermeabilidad más bien, por parte de ciertos sectores de la crítica, ante el género como categoría de análisis teórico.

Pero el riesgo que corren los trabajos sobre el género — como muchos trabajos sobre otras categorías excluidas de los relatos maestros nacionales en América Latina: las categorías de raza o de clase serían otras - es armar, a partir de la categoría excluida, un contrarrelato que se autoabastece. No pocos críticos, acaso yo misma, hemos cedido a esa tentación. El gesto lleva, o puede llevar, a resultados contraproducentes, es decir, a nuevos relatos si no maestros, “mini maestros”, a nuevas categorías estancas. Creo que esto se debe, en buena medida, a un intento (loable y por otra parte necesario) de recuperación histórica: se intenta dar nueva vigencia a textos olvidados, marginados, mezquinamente leídos pongamos por caso "literatura escrita por mujeres"ellos lecturas nuevas y desestabilizar, desde la orilla, perspectivas hegemónicas. Y es natural, aun lógico, armar con esos textos olvidados conjuntos inquisidores, cánones alternativos; pero es fácil naturalizar esas nuevas construcciones al punto que parezcan tan “centrales” como los mismos conjuntos que se busca desestabilizar, olvidando que son

\footnotetext{
${ }^{1}$ Para una lectura alegórica de este incidente, ver Mary Louise Pratt (190-191). Pratt comenta los aspectos utópicos de esta comunidad cuya naturaleza homosocial observa al pasar al describirla como un "paraíso masculinista".

2 Julio Ortega, “Carta de Chicago”, Excélsior, México, 16 de enero del 2000, y “El español en Chicago”, El País, Madrid, 25 de enero del 2000.
} 
inestables, móviles, necesariamente ambiguas, y que ahí reside, precisamente, su fuerza disruptora. Si bien el trabajo de archivo, absolutamente necesario como punto de partida de una reflexión acerca del género, es de enorme importancia, me gustaría pensar que los que trabajamos sobre esa categoría inestable que es el género lo hacemos a partir del género más que en el género, que buscamos articular no sólo la reflexión acerca del género sino (si se me permite el juego de palabras), la re-flexión, es decir, una nueva flexión en el texto cultural latinoamericano (en la totalidad de ese texto, no en partes selectas) que permita leer de otra manera, de diversas otras maneras. Esa nueva flexión, esa lectura o lecturas desviadas (como el desvío que llevaba a Sarmiento a Más-a-fuera), permite reconocer esos nudos de resistencia que señalaba Foucault dentro del espacio circunscrito de la institución, pasajeras heterotopías que se desvían del proyecto disciplinador. Si bien no bastan en sí para articular sistemas alternativos, quiero decir, sistemas de "estar en el mundo" (y aquí cabe preguntarse hasta dónde es deseable articular esos sistemas alternativos, so riesgo de "disciplinarlos”), esos nudos de resistencia (no sólo constituidos por el género) abren "fisuras culturales" (Richard 193), para usar el término de Nelly Richard, en los discursos establecidos.

¿Cómo operar esas fisuras culturales, es decir, cómo transformar la resistencia del género en intervención re-flexiva? Richard utliza el término en el contexto de las artes plásticas, se refiere memorablemente a la escandalosa circulación, en 1994, del "Simón Bolívar” travesti del artista Juan Dávila, como parte del proyecto de la Escuela de Santiago financiado por el Ministerio de Educación. El proyecto no sólo significaba una ruptura en sí - la instalación iconoclasta, exhibida por primera vez en una galería de Londres, de un Bolívar mestizo dotado de pechos, aros y medias de mujer, con el dedo anular de una mano provocadoramente erguido - sino que potenciaba, mediante la reproducción visual (la tarjeta postal) y su circulación, la visibilidad de esa ruptura. Así lo entendieron las fuerzas que denunciaron el ultraje y reclamaron reparación (la embajada de Venezuela, la prensa conservadora, el presidente del Senado chileno), es decir, como exceso visible que, en su descontrol mismo — la diseminación irrefrenable de la tarjeta postal ofensiva— ${ }^{3}$, amenazaba representaciones culturales hegemónicas.

Pero ¿cómo transformar esas fisuras culturales desde el género en intervenciones textuales, como reproducir, a nivel de la crítica, esa visibilidad con la que cuentan tanto las artes plásticas como las performativas? Es fácil pensar en intervenciones eficaces en esos campos: Jesusa Rodríguez, Tito Vasconcelos, Las Yeguas del Apocalipsis, Carmelita Tropicana, para citar algunos ejemplos. La performance del género es siempre proyecto desestabilizador. Lo que yo propondría como ejercicio crítico a partir del género es la intervención (ya que necesariamente no puede ser visible) de una relectura llamativa, en el doble sentido de este término, es decir notable, escandalosa si se quiere, y a la vez eficazmente interpeladora; una relectura no tanto para rescatar textos olvidados o "mal leídos” como indiqué, sino para fisurar lecturas establecidas. Por ejemplo: un Bolívar hibridizado y feminizado escandaliza a todo un establishment diplomático. Mabel Moraña

${ }^{3}$ Es interesante notar que, como anota la propia Richard, las mismas tarjetas postales fueron exhibidas dos años más tarde en la Galería Gabriela Mistral, también dependiente del Ministerio de Educación, sin escándalo. A las muchas razones que conjetura Richard para explicar este cambio de actitud, puede añadirse el hecho de que la movilidad de las tarjetas ha sido interrumpida, que la muestra las ha vuelto exhibición cuando antes eran circulación. 
ha visto con certeza la necesidad programática de ese gesto iconoclasta de "indagación genealógica” (67). No menos necesaria ni programática sería una indagación genealógica a partir del género. ¿Qué haría la crítica hegemónica latinoamericana, por ejemplo, con una lectura desde el género de Rodó que trabajara junto con sus textos publicados sus textos inéditos, no con afán de descubrir una sexualidad que permitiera integrarlo en un cánon alternativo sino para elaborar, desde ese mismo género, las nociones de vergüenza y de redención en Rodó para luego relacionarlas con su férreo proyecto de una ciudadanía sublime? Otro ejemplo: ¿qué doblez o qué flexión añadiría a las ideas recibidas de esa crítica sobre ateneos o cenáculos latinoamericanos (de hecho, con pocas excepciones, se ha pensado bien poco en ese fenómeno como fenómeno continental y no como suma de casos aislados), qué doblez añadiría, repito, la inclusión de la utópica Colonia Tolstoyana de Augusto D’Halmar, claramente disidente en términos de género y sexualidad, como un lugar otro donde pensar la homosociabilidad, que es la base misma de los proyectos de nación? Un tercer ejemplo: ¿cómo pensar el conservadorismo ideológico de una Teresa de la Parra, una Lidia Cabrera, o incluso una Gabriela Mistral, no como mera manifestación de una ideología reaccionaria sino (y sé que esto no es fácil) como reacción ante procesos de modernización que sólo proponen heteronormativides reproductivas? Y por último, en este repertorio al cual podrían añadirse tantas escenas más: ¿cómo analizar desde el género la popularidad de ciertos intelectuales — pienso en un Salvador Novo, un Manuel Mujica Láinez, esos Liberaces de la cultura latinoamericana — quienes visibilizan a ultranza una sexualidad disidente a través del trabajo de pose a la vez que son reconocidos, incluso celebrados, como portavoces de un estado conservador cuya doxa propagan? Creo que el campo está abierto para pensar desde el género; pero para que ese pensamiento sea eficaz, para que su capacidad interventora se potencie, es indispensable articular ese pensamiento desde el género como incidencia en otros discursos, como intervención en pasadas lecturas, como cruce y como relaciones, por problemáticas que parezcan. Sólo así logrará la cuestión del género —o por lo menos así lo espero- la eficacia, por pasajera no menos memorable, de las tetas de Bolívar.

\section{Bibliografía}

Moraña, Mabel. “Narrativas protonacionales: el discurso de los libertadores”. Políticas de la escritura en América Latina. Caracas: Ediciones Excultura, 1997.

Pratt, Mary Louise. Imperial Eyes: Travel Writing and Transculturation. Nueva York/ Londres: Routledge, 1992.

Richard, Nelly. Residuos y metáforas: ensayos de crítica cultural sobre Chile de la transición. Providencia, Santiago de Chile: Editorial Cuarto Propio, 1998.

Sarmiento, Domingo Faustino. Viajes por Europa, Africa y América 1845-1847. NanterreMadrid: AALCA XX, Fondo de Cultura Económica, 1996. 